\title{
Experimental study of interfacial heat flux and surface temperature by inverse analysis with thermocouple (fully embedded) during hot steel strip rolling
}

\author{
Daniel Weisz-Patrault ${ }^{1, a}$, Alain Ehrlacher $r^{1, b}$, Nicolas Legrand ${ }^{2, c}$, Nathalie \\ Labbe $^{2, d}$, Jaroslav Horský ${ }^{3, e}$, Tomáš Luks ${ }^{3, f}$ \\ ${ }^{1}$ Ecole Ponts ParisTech, UR Navier, 6 \& 8 Ave Blaise Pascal, 77455 Marne La Vallee, France \\ ${ }^{2}$ ArcelorMittal Global Research \& Development, Maizière Process Voie Romaine, BP 30320 F- \\ 57283 Maizières-lès-Metz Cedex \\ ${ }^{3}$ Brno University of Technology, Faculty of Mechanical Engineering, Heat Transfer and Fluid Flow \\ Laboratory, Technicka 2896/2, 61669 Brno, Czech Republic \\ adaniel.patrault@enpc.fr, ${ }^{b}$ alain.ehrlacher@lami.enpc.fr, ${ }^{\circ}$ nicolas.legrand@arcelormittal.com, \\ dnathalie.labbe@arcelormittal.com, ${ }^{\mathrm{e}}$ horsky@fme.vutbr.cz, 'luks@LPTaP.fme.vutbr.cz
}

Keywords: Inverse sensor, Thermocouple, Experimental study, Steel Strip Rolling

Abstract: Knowledge of temperature distribution in the roll is fundamental aspect in cold rolling. An inverse analytical method has been previously developed to determine interfacial heat flux and surface temperature by measuring the temperature with a thermocouple (fully embedded) at only one point inside the roll. On this basis some pilot mill tests have been performed. The temperature sensor, the calibration procedure and rolling tests at different strip rolling conditions $(5 \%, 10 \%$, $15 \%$ and 20\%) are described. Results show a good agreement with well-known theoretical models. Moreover the CPU times of the method (around $0.05 \mathrm{~s}$ by cycle) enable an online control of the rolling process.

\section{Introduction}

In steel strip rolling, two rolls are used as tools to reduce the thickness of a workpiece. For hot rolling conditions, knowledge of the heat fluxes entering the roll is fundamental for evaluation of thermal fatigue, which is one of the major factor of wear on rolls, as investigated by Coral et al. (2004) [1] or Li et al. (2007) [2]. Fatigue load is completely negligible for cold rolling conditions. However, in the roll gap the characterization of the thermal problem would lead to knowledge of viscosity and thickness of the lubricant. Moreover the roll expansion and thermal crown are important factors of the prediction of the flatness of products.

Several contributions use inverse methods to interpret experimental measurements. Tavares et al. (2001) [3] proposed an inverse method based on one-dimensional model (Lagrangian coordinate system moving at the same speed as the roll). The response time of the thermocouple is studied and a proper correction of the temperature data is introduced. Kotrbacek et al. (2006) [4] proposed a comprehensive numerical inverse approach, where the thermocouple is modelled to interpret measurements to optimise the cooling of the roll.

In the present paper, an analytical inverse method (previously developed by Weisz-Patrault et al. [5]) is used to interpret the measurements of a fully embedded thermocouple. The main improvement of this inverse method is the very short CPU times (around $0.05 \mathrm{~s}$ by cycle), which could be used for real time control of rolling processes.

\section{Thermocouple and acquisition}

The thermocouple is located in a cylindrical plug. The work roll is drilled then the plug is inserted and glued into the roll. The surface of the roll is then reground to avoid marks on the strip. The thermocouple is placed in a slot made by milling (at the surface of the plug) and brazed to the rest of body. A solder material covers the thermocouple. The thermocouple is placed along the axis 
of the roll in order to be parallel to the isotherms. Fig. 1 shows a schematic view of the plug inside the roll and a picture.
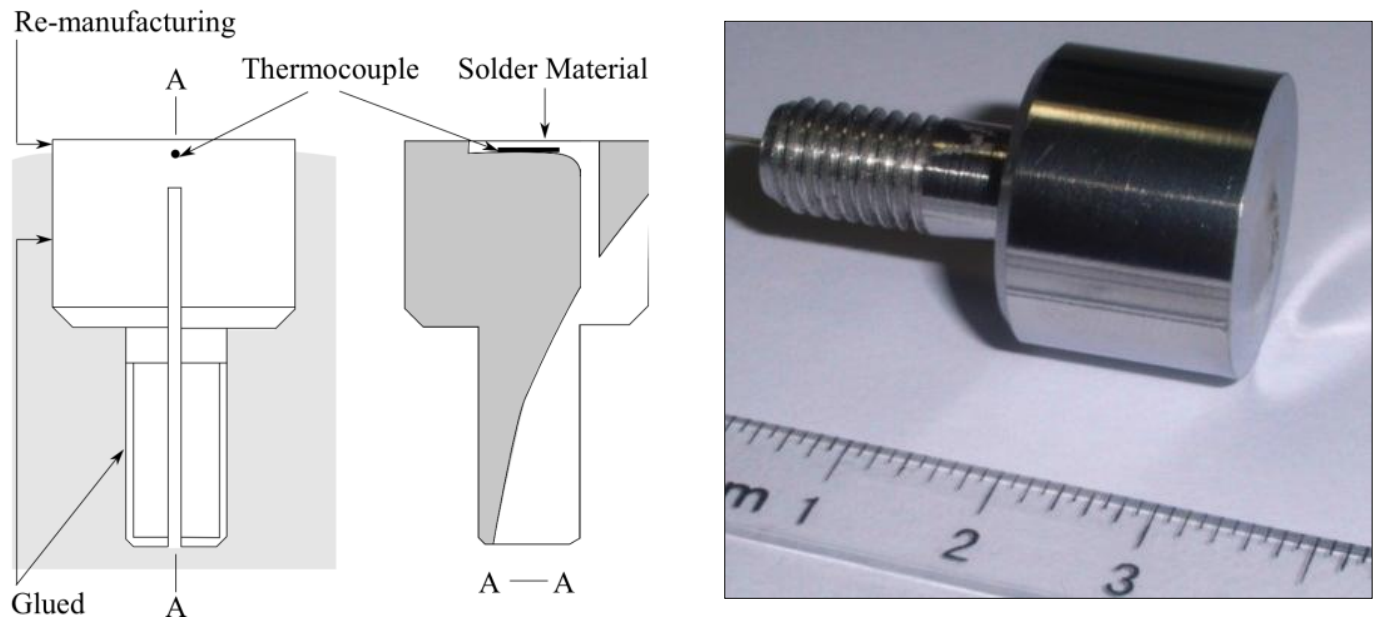

Fig.1 Plug with thermocouple

A high resolution (16 bits) data acquisition system has been specifically designed. The system is embarked with the rotating roll: the telemeters encoders and transmitters are fixed directly to the roll chock which enables to supply the embarked acquisition system and to collect the signal. The signal is then transferred to the main data acquisition system by wireless inductive transmission.

\section{Material properties}

The thermocouple is actually a multilayered component. The wire of the thermocouple is surrounded by an electrical insulation and a shield embedded in the solder material. The insulation is responsible for a delay in the sensor response. However considering the low rotation speed of the present study, these effects have not been modelled. The material considered for the inverse calculation is the solder material. The inverse solution used for interpreting the measurements requires a thermal diffusivity (and thermal conductivity for heat flux) independent on the temperature. The Fig.2 shows these two quantities as functions of temperature. From these graphs, mean values are extracted for use in the inversion: $\mathrm{D}=4.2 \mathrm{~mm}^{2} / \mathrm{s}$ (thermal diffusivity) and $\lambda=0.0173$ $\mathrm{W} / \mathrm{mm} / \mathrm{K}$ (thermal conductivity).

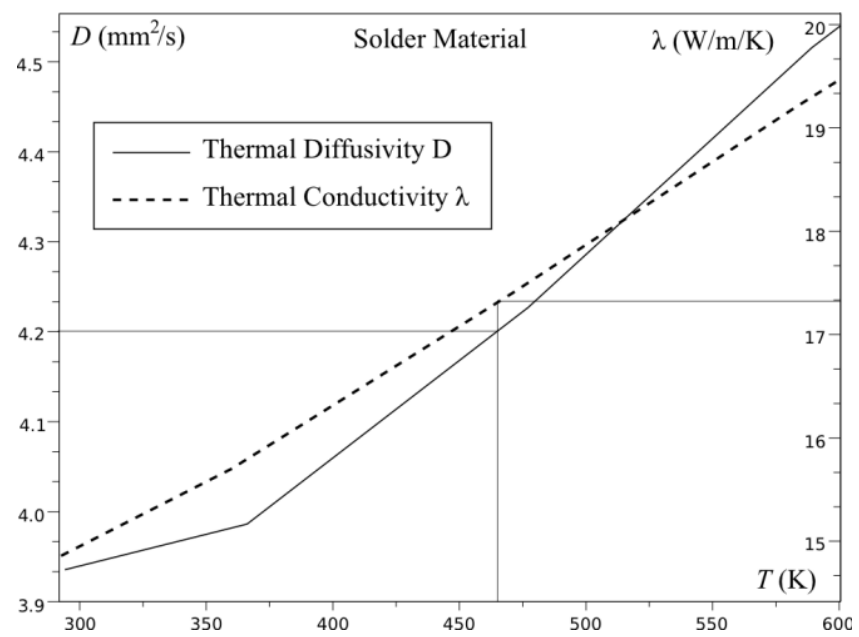

Fig.2 Thermal diffusivity and thermal conductivity

\section{Calibration}

The depth of the thermocouple is unknown, because of the solder material and the grinding. Therefore a calibration is used by spraying warm water on the surface of the roll (no rotation). The 
roll being initially at the room temperature, the response of the thermocouple is a concave increasing curve as shown in Fig.3. The Heat Transfer Coefficient (HTC) between water and steel (estimated to $19750 \mathrm{~W} / \mathrm{m}^{2} / \mathrm{K}$ ) is used to determine the heat flux entering the roll. Even if the water does not surround the entire roll, it is almost equivalent for the signal delivered by the thermocouple that is heated by water. Therefore a well known analytical direct solution (based on zero-th Bessel function and time dependent exponentials) is used for this problem (constant surrounding temperature). The depth of the thermocouple is determined by matching the measurements and the calculated temperature. The thermocouple is estimated to be at $0.51 \mathrm{~mm}$ from the surface of the roll, which is close from the designed value $(0.5 \mathrm{~mm})$.

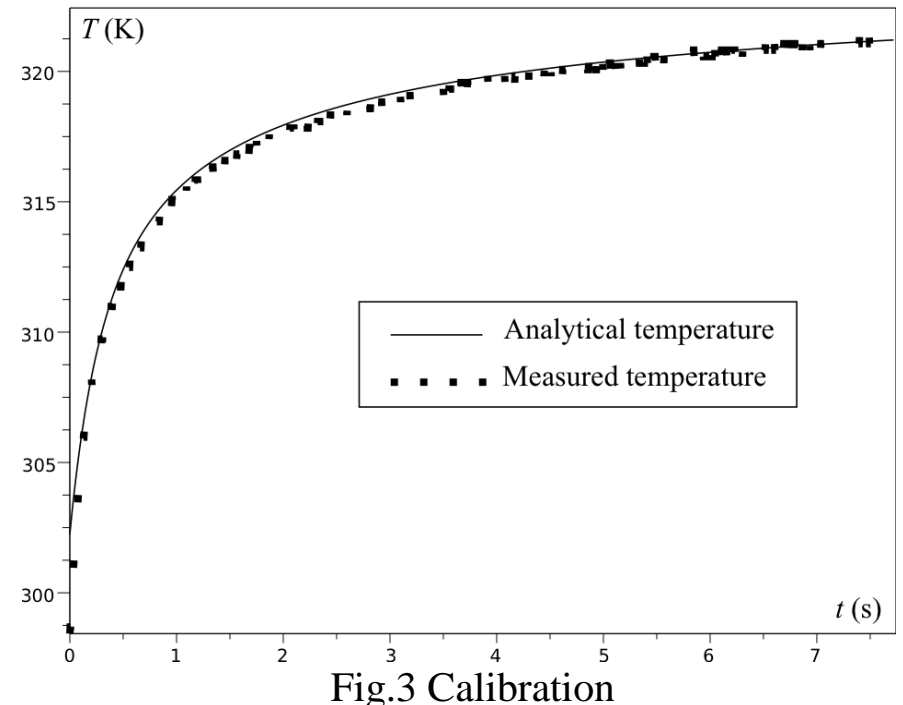

\section{Results}

Rolling conditions are listed in Table.1. The work roll diameter is $469 \mathrm{~mm}$. The cooling of the roll is done only by ambient air. The frequency of acquisition is $10 \mathrm{kHZ}$ except for $20 \%$ reduction $(5 \mathrm{kHZ})$. Fig.5 presents the measured temperatures for all reductions. A small level of noise $(+/-0.5 \mathrm{~K})$ and a temperature increase between the beginning and the end of each cycle (transient state) are observed. The noise is not filtered because the inverse analysis developed by Weisz-Patrault et al. [5] is already a filter (expansion into a Fourier series of the inputs multiplied for each harmonic by a factor).

\begin{tabular}{lllll}
\hline $\begin{array}{l}\text { Reduction } \\
(\%)\end{array}$ & $\begin{array}{l}\text { Initial thickness } \\
(\mathrm{mm})\end{array}$ & $\begin{array}{l}\text { Final thickness } \\
(\mathrm{mm})\end{array}$ & $\begin{array}{l}\text { Rotation speed } \\
(\mathrm{rad} / \mathrm{s})\end{array}$ & $\begin{array}{l}\text { Strip temperature } \\
(\mathrm{K})\end{array}$ \\
\hline 5 & 57 & 54 & 6.33 & 1335 \\
\hline 10 & 54 & 49 & 6.33 & 1351 \\
\hline 15 & 51 & 43 & 6.33 & 1335 \\
\hline 20 & 48 & 38 & 6.33 & 1275 \\
\hline
\end{tabular}

Tab.1 Pilot rolling conditions

Figures 6 and 7 present (for the first cycle) the surface temperature and the interfacial heat flux reconstructed by inverse analysis. The higher the reduction is and the higher the interfacial heat flux and therefore the temperature peak at the surface of the roll are. This is due to the fact that the friction level and the plastic deformation increase. 


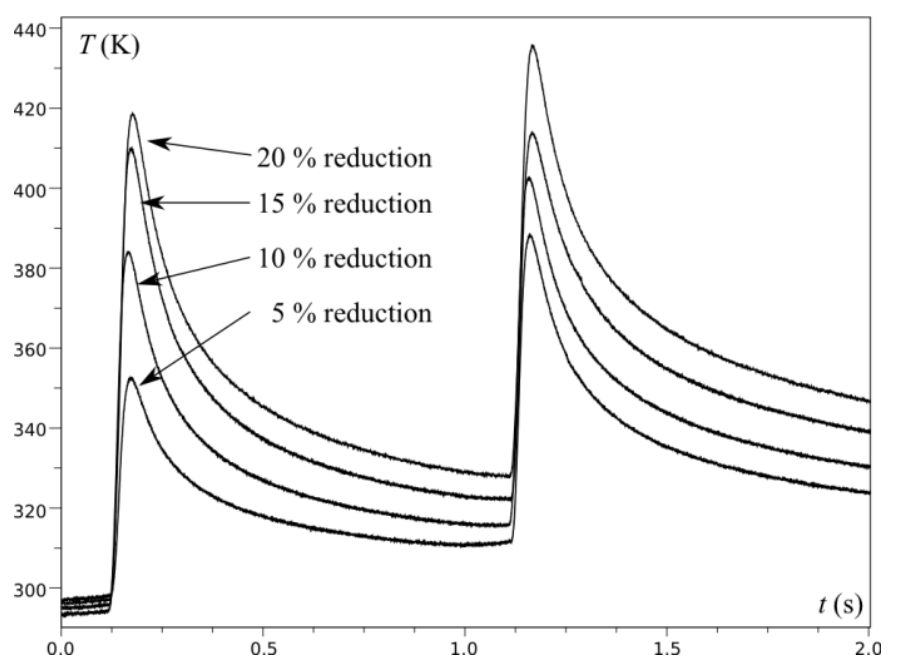

Fig 5. Temperature measurements for various reductions

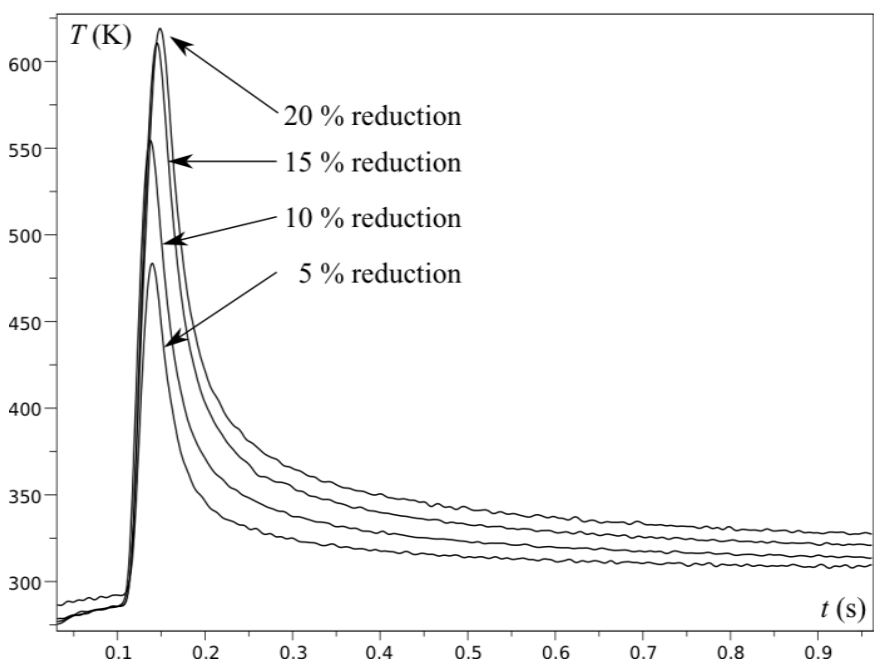

Fig 6. Surface temperatures (estimated by inverse analysis)

Fig. 7 shows the heating in the roll gap (sharp gradient) but also the cooling by air elsewhere. At the exit of the roll gap the cooling is higher than in the other parts because the difference of temperature between the roll and the air is much more significant at the exit of the roll gap.

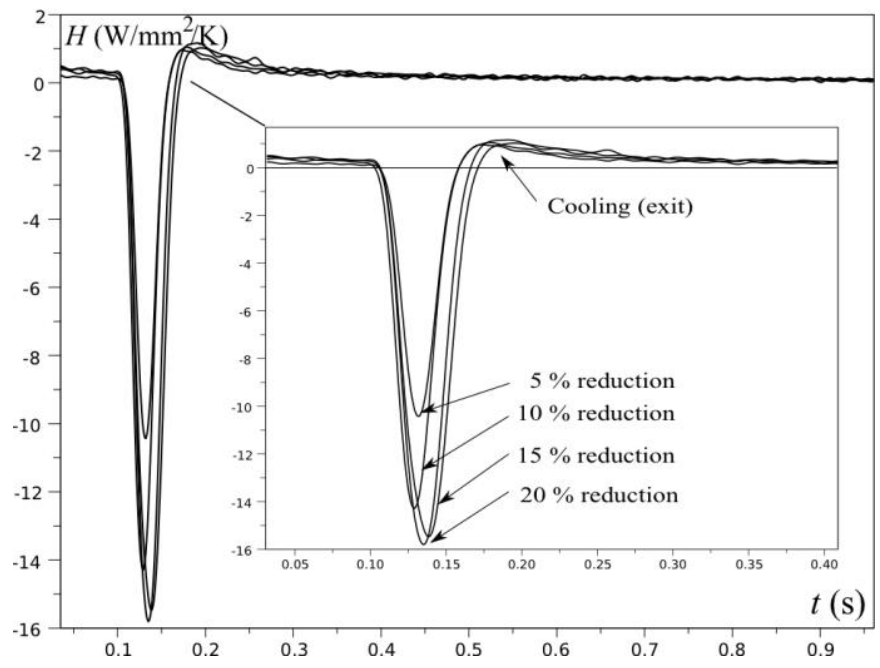

Fig 7. Interfacial heat fluxes (estimated by inverse analysis) 


\section{Summary}

This paper presents an experimental study based on the interpretation of measured temperatures (thermocouple fully embedded inside the roll) by inverse analytical method. The surface temperature and the interfacial heat flux present good agreement with classical predictive models like the old analytical model of Tseng et al. (1990) [6]. This study emphasizes the heat due to friction and plastic deformation because several reductions have been tested.

Moreover the very short computation times of the inverse analysis (around $0.05 \mathrm{~s}$ by cycle) enables its use in a close-loop control during rolling process.

\section{References}

[1] R.L. Corral, R. Colas, A. Perez: Modeling the thermal and thermoelastic responses of work rolls used for hot rolling steel strip. Journal of Materials Processing Technology, Vol. 153 (2004), p. 886-893

[2] C.-S. Li, H.L. Yu, G.Y. Deng, X.H. Liu, G.-D. Wang: Numerical simulation of temperature field and thermal stress field of work roll during hot strip rolling. Journal of Iron and Steel Research International, Vol. 14 (2007), p. 18-21

[3] R. Tavares, M. Isac, F. Hamel, R. Guthrie: Instantaneous interfacial heat fluxes during the 4 to $8 \mathrm{~m} / \mathrm{min}$ casting of carbon steels in a twin-roll caster. Metallurgical and Materials Transactions BProcess Metallurgy and Materials Processing Science, Vol. 32 (2001), p. 55-67

[4] P. Kotrbacek, M. Raudensky, J. Horsky, M. Pohanka: Experimental study of heat transfer in hot rolling. Revue de Metallurgie-Cahiers d'Informartions Techniques, Vol. 103 (2006), p. 333-341

[5] D. Weisz-Patrault, A. Ehrlacher, N. Legrand: Evaluation of temperature field and heat flux by inverse analysis during steel strip rolling. International Journal of Heat and Mass Transfer, Vol. 55 (2012), p. 629-641

[6] A. Tseng, S. Tong, S. Maslen, J. Mills: Thermal behavior of aluminium rolling. Journal of Heat Transfer, Vol. 112 (1990), p. 301-307 